\title{
Historia de la Psicología Interamericana: Sociedad Interamericana de Psicología (1951)
}

\author{
Miguel Gallegos \\ Universidad Nacional de Rosario - CONICET (Argentina)
}

History of the Interamerican Psychology: The Interamerican Society of Psychology (1951)

The purpose of the present article is to justify the history of the Interamerican Psychology regarding the foundation of the Interamerican Society of Psychology (ISP), in 1951. Although other studies had addressed the development of the Interamerican Psychology, none of them had justified its history. In that sense, the present work addresses the following issues: 1) the foundation of the ISP; 2) the historical context of this foundation; 3 ) the more important outcomes of this foundation; 4) the factors that justify the history of the Interamerican Psychology. In sum, the present work suggests that the history of the Interamenrican Psychology is the history of the connections and the creation of the ISP was the key element that promoted those connections.

Keywords: Interamerican Society of Psychology, history, interamerican psychology.

\begin{abstract}
Este trabajo se plantea justificar la historia de la psicología interamericana a partir de establecer como dato histórico la constitución de la Sociedad Interamericana de Psicología (SIP), en diciembre de 1951. Si bien otros trabajos ya se han referido a la psicología interamericana, no obstante, aun no se ha justificado su sentido histórico. En base a esta premisa, el trabajo se propone desarrollar: 1) la fundación de la SIP; 2) el contexto de fundación de la SIP; 3) los desarrollos más importantes de la SIP; 4) las razones que justifican la historia de la psicología interamericana. En su conjunto, el trabajo abona a la idea de que la historia de la psicología interamericana es la historia de las conexiones y la creación de la SIP es el dato histórico que permite esas conexiones.

Palabras clave: Sociedad Interamericana de Psicología, historia, psicología interamericana.
\end{abstract}

Correspondence concerning this article should be addressed to Miguel Gallegos. Facultad de Psicología. Universidad Nacional de Rosario. IRICE-CONICET. Bv. 27 de Febrero 210 Bis. Código Postal: 2000 Rosario (Argentina). E-mail: maypsi@yahoo.com.ar 
La historiografía de la psicología, es decir, la forma en la que se construye un relato acerca del pasado, ha delineado diversas formas de presentar el pasado de la psicología. Para el caso, se puede encontrar una historia de la psicología que se remonta hasta el período de la filosofía griega y repasa el devenir de las ideas psicológicas durante varias centurias hasta principios de siglo XX (Brett, 1972; Mueller, 1976). Otras historias abordan directamente la psicología del siglo XX (Heidbreder, 1979).

Existen tratados y manuales que pasan revista por diferentes aspectos teóricos y metodológicos de la psicología (Guillaume, 1959; Telford \& Sawrey, 1977; Thompson \& DeBold, 1980), así como un conjunto heterogéneo de introducciones a la psicología (García-Vega, Moya-Santoyo, \& Rodríguez-Domínguez, 1992; Reuchlin, 1973; Wolff, 1970; Zunini, 1965). Algunos enfatizan el aspecto experimental de la psicología (Boring, 1978; Fraisse \& Piaget, 1976; Garrett, 1962), otros el aspecto social (Farr, 1998) y otros el aspecto psicodinámico (Bercherie, 1988).

Algunas obras matizan las figuras de los pioneros (Ardila, 1971; Fancher, 1979). Desde luego, existen aquellas historias que subrayan el lugar de origen de las ideas, escuelas o corrientes psicológicas. En este caso, algunas historias ofrecen una visión norteamericana (Zazzo, 1964) y otras ofrecen una visión más enfocada en España (Carpintero, 1994; García-Vega \& Moya-Santoyo, 1993) o en Rusia (Galperín, 1976; García-Vega, 1993).

Otros trabajos se enfocan específicamente en la historia de la psicología de algún país determinado. En esta dirección, existe una amplia documentación en Argentina (Dagfal, 2009; Gallegos, 2005; Gentile, 2003; Klappenbach, 1998, 2002, 2006; Rossi, 1994, 1997, 2005; Talak, 2000; Vezzetti, 1988) y Brasil (Antunes, 1995; Filho, 1970; Gomes, 1992; Massimi, 1990). También se encuentra literatura histórica para Chile (Bravo, 2004; Ligüeño \& Parra, 2007; Salas, 2010; Salas \& Lizama, 2009), Colombia (Ardila, 1973, 1993), Perú (Alarcón, 2000; León, 1993), Paraguay (García, 2004, 2005, 2006, 2007, 2008, 2010) y México (SánchezSosa, 1997; Valderrama, Colotla, Gallegos, \& Jurado, 1994).

En este recuento historiográfico no faltan las historias regionales, como por ejemplo, la psicología en América Latina (Alarcón, 2002, 2004; Alonso \& Eagly, 1999; Ardila, 1986, 2004; Gallegos, 2009; Klappenbach \& Pavesi, 1994; Sánchez-Sosa \& Valderrama-Iturbe, 2001; Torre, 1991, 2010), la psicología en El Caribe (Álvarez-Salgado, 2000; Roca de Torres, 2003) o la psicología en el Mercosur (Vilanova \& Di Doménico, 1999).

De acuerdo a esta última forma de abonar a la historia de la psicología, ¿sería lícito presentar una historia de la psicología interamericana? De ser posible, ¿bajo que parámetros y operaciones históricas sería posible? ¿Qué delimitaría una historia de la psicología interamericana? ¿Cuál sería su sentido histórico?

Desde el comienzo, no existe ningún impedimento para referir una psicología interamericana, como algunos auto- res ya lo han manifestado (véase Díaz-Guerrero, 2004; Holtzman, 1979; Urra, 2004, 2003). No obstante, sería conveniente justificar su sentido histórico, aclarando que se trataría de una psicología que se desarrolla en el continente americano, contemplando tanto la complejidad de la extensión y diversidad geográfica como el contexto multicultural y multilingüe.

Ahora bien, si ya se ha reconocido la complejidad de englobar una historia de la psicología en América Latina (Ardila, 1986), y más aún, una historia que contenga la psicología en El Caribe y Centro América (Álvarez-Salgado, 2000; Roca de Torres, 2003), cómo sumar la psicología en Estados Unidos y Canadá, para referir una psicología interamericana.

Para ello, es necesario buscar un elemento que funcione como conector de aquella complejidad señalada. En este sentido, es posible plantear a la creación de la Sociedad Interamericana de Psicología (SIP), en 1951, como un elemento que permite establecer un criterio demarcatorio, y de esta forma, habilitar el sentido de una historia de la psicología interamericana.

Desde ya, referir este acontecimiento fundacional no inhabilita que se construya una historia de la psicología interamericana anterior a 1951. Sin embargo, la fundación de la SIP puede ser ubicada legítimamente como el primer acontecimiento que, no sólo desde el punto de vista institucional, sino también, desde la movilización de recursos humanos, funcione como parámetro histórico.

En base a este marco general de ideas, el presente trabajo se plantea desarrollar cuatro objetivos. En primer lugar, destacar el momento fundacional de la SIP, recuperando fuentes documentales de primera mano. En segundo lugar, contextualizar el tiempo de creación de la SIP. En tercer lugar, describir las realizaciones más importantes durante sus sesenta años de existencia. En cuarto lugar, justificar y dar razones de por qué es lícito plantear una historia de la psicología interamericana a partir de la constitución de la SIP.

\section{La fundación de la SIP}

La historia de la SIP, sus cultores y sus realizaciones más importantes han sido destacadas en diversas oportunidades (véase Alonso \& Nicenboim, 1999; Álvarez \& Boni1la, 1995; Angelini, 1979; Alarcón, 2004; Ardila, 1986, 2004; Colotla \& Urra, 2006; Ferdman, 2000; Ferdman \& VanOss, 1999; Gallegos, en prensa; Klappenbach, 2004; Maluf, 2004; Urra, 2004; Villegas, 2004). No obstante, aun reconociendo estas diversas producciones, todavía es posible agregar algunos datos históricos que no han sido relevados.

La SIP fue fundada el 17 de diciembre de 1951, en la ciudad de México, por un grupo de psiquiatras y psicólogos que se encontraban en la citada ciudad, a propósito de la realización del VI Congreso Internacional de Salud Mental (Angelini, 1979; Ardila, 1986, 2004; Colotla \& Urra, 
2006; Villegas, 2004). Según informa Robles (1955), entre los miembros que figuran como promotores de aquella fundación se encuentran (Tabla 1):

Tabla 1

Primer Comité Directivo de la Sociedad Interamericana de Psicología

\begin{tabular}{lll}
\hline Cargo & Nombre y Apellido & País \\
\hline Presidente & Eduardo Krapf & Argentina \\
Vicepresidente & Werner Wolff & Estados Unidos \\
Secretario General & Oswaldo Robles & México \\
Tesorero & Hernán Vergara & Colombia \\
Vice-presidentes asociados & & \\
& Carlos Nassar & Chile \\
& Jaime Barrios Peña & Guatemala \\
& William Line & Canadá \\
\hline
\end{tabular}

Fuente: elaborado en base a Robles (1955:745).

Para más detalles, es interesante reproducir el reporte del primer secretario de la SIP, puesto que allí se certifica la fundación de la sociedad, se consignan algunas de las contingencias que rondaron a la creación de la sociedad y se mencionan las primeras tareas de gestión que se trazó la recientemente constituida comisión directiva.

"En la ciudad de México, a las quince horas treinta minutos del día diecisiete del mes de diciembre de 1951, en el Edificio Central del Seguro Social, se reunió un grupo de especialistas en Psicología para discutir la proposición del Dr. Jaime Barrios Peña, Delegado de Guatemala, secundada por los representantes de Argentina, Canadá, Brasil, U.S.A., Colombia y México, sobre la creación de la Sociedad Interamericana de Psicología.

Se precedió a nombrar Presidente de Debates, designándose al Dr. Werner Wolff.

Después de ser ampliamente discutidos, se aprobaron los siguientes puntos:

$1^{\circ}$ Que el Comité Directivo Provisional sea integrado por los Representantes de los Países que suscribieron la invitación.

$2^{\circ}$ Que dentro de este Comité se estableciera una jerarquía para el mejor cumplimiento de las funciones.

$3^{\circ}$ Que para coordinar el trabajo se nombrará Jefes de Zonas que figurarán como colaboradores de la Secretaría General.

$4^{\circ}$ Que el Comité Directivo Provisional designe una Comisión para redactar un proyecto de estatutos, que serán enviados a los Jefes de Zona, a fin de recoger las opiniones de los Países que comprenden aquella que les haya sido señalada.

$5^{\circ}$ Que se haga el registro de la Sociedad Interamericana de Psicología, como sociedad Autónoma con Legalidad internacional. $6^{\circ}$ Que el Comité Directivo Provisional se avoque a organizar la primera reunión INTERAMERICANA DE PSICOLOGÍA" (Robles, 1955: 745, subrayados en el original).

De esta cita es posible extraer varias informaciones significativas. En primer lugar, la constitución de la primera comisión directiva de la SIP, aunque provisoria, fue verdaderamente representativa, ya que contó con una amplia cobertura de países. En esta inicial comisión de la SIP se hace visible el sentido de referir una historia de la psicología interamericana, que probablemente no encuentre una antecedente similar en el pasado de la psicología en las Américas.

En segundo lugar, como en toda organización, era necesaria una estructura de funcionamiento que no sólo distribuyera responsabilidades, sino además, pudiera coordinar las tareas en el amplio continente americano, en un tiempo en el que las comunicaciones no funcionaban con la celeridad del presente.

En tercer lugar, se establecía un funcionamiento de gestión distribuido zonalmente, aunque coordinado por la secretaría general. Si bien esta forma de organización no funcionó del todo aceitadamente al comienzo, con el tiempo y algunos cambios, fue la forma que adoptó la organización de la SIP. En estricto sentido, originalmente se había propuesto crear ramas nacionales de la SIP, pero en la práctica la única que se constituyó fue la Rama Mexicana de la SIP.

En cuarto lugar, se establecía el encargo de redactar el proyecto de estatuto de la SIP, que fue depositado en la persona de Jaime Barrios Peña, delegado por Guatemala (Robles, 1955) y el registro legal de la sociedad. Se sabe que los estatutos de la SIP fueron aprobados durante el segundo congreso de la SIP, en México, en 1954 (Ferdman, 2000).

Por último, no menos importante, se proyectaba la realización de la primera reunión interamericana de psicólogos. Probablemente, una de las realizaciones más importantes de la SIP. Los congresos interamericanos de psicología, realizados desde 1953, son la representación más cabal de la trascendencia e importancia de la SIP en la psicología interamericana (Gallegos, en prensa).

Visiblemente, la creación de la SIP aparece como dato histórico que marca un antes y un después en la psicología que tuvo lugar en las Américas. Es a partir de la fundación de la SIP que los lazos científicos, profesionales, académicos e institucionales entre la psicología del norte y del sur americano se hicieron más estrechos. Pues ese fue el objetivo con el que inició sus actividades.

"Se dejó establecido que la naturaleza, el propósito, la finalidad de la S.I.P. era la de una organización autónoma internacional de los psicólogos de los países americanos, encargada de promover la cooperación de los psicólogos de los países de América en la docencia, la investigación y el ejercicio profesional de la Psicología, fomentando la creación de grupos de estudio, la celebración de reuniones nacio- 
nales e internacionales, la edición de una Biblioteca Interamericana de Psicología, la fundación de un Boletín Interamericano de Psicología y la constitución de un fondo que permitiera el intercambio de profesores y la facilitación de becas para la ampliación de estudios e investigaciones" (Actas, 1955: 770-771).

Nunca antes en la historia de la psicología interamericana se había iniciado o propuesto un programa como el que se inicia con la SIP. De ahí su carácter de acontecimiento histórico y su proyección para la psicología interamericana.

\section{El contexto de creación de la SIP}

Contextualmente, la fundación de la SIP ocurre en un tiempo en el que se producen varios acontecimientos sociales, culturales, políticos y científicos importantes. En primer lugar, la creación de la SIP se ubica en el tiempo de posguerra y el inicio de la llamada guerra fría. La finalización de la II Guerra Mundial tuvo diversas consecuencias para el mundo, fundamentalmente, en el reacomodamiento geopolítico de los países (Hobsbawm, 2007). Para la psicología y los psicólogos supuso un nuevo reto: si antes los psicólogos habían prestado sus servicios a las cuestiones bélicas, ahora deberían contribuir a la paz y el desarrollo de las naciones.

En segundo lugar, a consecuencia del período bélico europeo, se produjo una fuerte oleada inmigratoria de varios cultores de la psicología internacional hacia diversos países del continente americano. Algunos se establecieron en el norte y otros en el sur (véase Ardila, 1986, 2004; Carpintero, 1993, 2005; Díaz-Guerrero, 1994a; Geuter \& León, 1997; Jacó-Vilela, 2000; León, 1997; León \& Gueter, 1993; Stubee, 1988; Torre, 2010). En las trayectorias de Eduardo Krapf y Werner Wolff, primer presidente y vicepresidente de la SIP, respectivamente, encontramos esta trastienda histórica (Gallegos, en prensa).

A este acontecer histórico, se suma el conflicto de la Guerra Civil Española que también supuso la inmigración de diversos profesionales hacia el continente americano (Carpintero, 1993, 1997, 2004). Fueron muchos los que peregrinaron por las tierras americanas, principalmente, en la parte hispanoparlante.

En tercer lugar, las actividades científicas y tecnológicas comenzaron a tener una mayor incidencia en la vida social y cultural de las naciones, no sólo en las actividades bélicas, sino también en la importancia otorgada a las posibles contribuciones sociales y económicas que se podían esperar de sus avances (Bell, 1973; Ben-David, 1974; Bernal, 1979; Elzinga \& Jamison, 1996; Price, 1973; Salomon, 1996). En este punto, no es casual que paralelo a la creación de la SIP, también se formara la International Union of Psychological Science (IUPsyS), en julio de 1951 (Holtzman, 1976; Nuttin, 1976; Rosenzweig \& Holtzman, 1993; Rosenzweig, Holtzman, Sabourin, \& Bélanger, 2000; Rusell, 1966).
La constitución de la IUPsyS ya se venía delineando desde 1948 y representa uno de los hitos de la internacionalización de la psicología. Tal internacionalización había comenzado tempranamente con el traslado de varios norteamericanos hacia Leipzig con el objetivo de estudiar psicología con Wundt (Langfeld, 1955). No obstante, el punto de inflexión de la internacionalización de la psicología, ocurre con la realización del Primer Congreso Internacional de Psicología Fisiológica, reunido en Paris, en 1889 (véase Anónimo, 1892; Anónimo, 1976; Ardila, 1972; Lunt, 2005; Lunt \& Poortinga, 1996; Montoro, Carpintero, \& Tortosa, 1983; Piéron, 1954). En ese acontecer histórico, la creación de la SIP puede verse como una internacionalización a escala interamericana.

En cuarto lugar, la SIP se funda en un tiempo en el que se produce una avanzada de la profesionalización del psicólogo. Aunque en Estados Unidos y Canadá, la profesionalización ya tenía un largo camino recorrido, no obstante, el período de posguerra significó una profundización de los quehaceres profesionales del psicólogo en sendos países (véase Adair, 1999; Benito, 2009; Benjamin, 2001; Camfield, 1973; Cook, 1965; Conway, 2010; Gallegos, 2010a; Klappenbach, 2003; McGovern, 1992; Sánchez-González, 2003; Wright, 1974).

Por su parte, en América Latina recién comenzaban a formase los primeros psicólogos, a partir de la inauguración de las carreras universitarias de psicología. Los primeros programas de formación universitaria se crean oficialmente en Chile en 1946 y en Colombia en 1947, aunque las actividades de enseñanza comienzan al año siguiente en sendos países (véase Ardila, 1973,1986, 1993; Gallegos, 2008, 2009, 2011; Gallegos, Reynaldo \& Catini, 2010; Klappenbach \& Pavesi, 1994; Ligüeño \& Parra, 2007; Salas \& Lizama, 2009; Sánchez-Sosa \& ValderramaIturbe, 2001).

Sobre la base de este contexto se desplegaron las diversas actividades de la SIP. Guerra, inmigración, ciencia, tecnología y profesionalización no sólo son los conceptos que podrían enmarcar la constitución de la SIP, sino además, las características singulares con las que se desarrolló la psicología interamericana hacia mediados de siglo XX.

\section{Presidentes de la SIP}

Durante sus sesenta años de desarrollo institucional, científico y profesional, la SIP ha contado con diversas comisiones directivas, encargadas de llevar a cabo los propósitos que le dieron origen. En la Tabla 2 se mencionan todos los presidentes que ha tenido la sociedad hasta el presente.

Fiel a su estructura de organización proyectada inicialmente, la SIP ha tratado de mantener una gestión representativa de las Américas. Esto puede verse reflejado en los sucesivos cargos presidenciales, con la alternancia de representantes latinoamericanos y norteamericanos. 
Tabla 2

Presidentes de la Sociedad Interamericana de Psicología

\begin{tabular}{|c|c|c|}
\hline Nombre y Apellido & País & Período \\
\hline Eduardo Krapf & Argentina & $1951-1953$ \\
\hline Oliver Brachfeld & Venezuela & $1953-1955$ \\
\hline Wilard C. Olson & Estados Unidos & $1955-1956$ \\
\hline Otto Klineberg & Estados Unidos & $1956-1957$ \\
\hline Guillermo Dávila & México & $1957-1959$ \\
\hline Gustave M. Gilbert & Estados Unidos & 1959-1961 \\
\hline José A. Bustamante & Cuba & 1961-1963 \\
\hline Harold H. Anderson & Estados Unidos & 1963-1964 \\
\hline Carlos A. Seguin & Perú & $1965-1966$ \\
\hline Wayne H. Holtzman & Estados Unidos & $1966-1967$ \\
\hline Rogelio Díaz Guerrero & México & 1967-1969 \\
\hline Robert M. Malmo & Canadá & 1969-1971 \\
\hline Arrigo L. Angelini & Brasil & $1971-1973$ \\
\hline David Belanger & Canadá & $1973-1975$ \\
\hline Rubén Ardila & Colombia & 1975-1976 \\
\hline Herbert C. Kelman & Estados Unidos & 1976-1979 \\
\hline Aroldo Rodrígues & Brasil & 1979-1981 \\
\hline Luis F. S. Natalicio & Estados Unidos & 1981-1983 \\
\hline Isabel Reyes Lagunes & México & 1983-1985 \\
\hline Harry Triandis & Estados Unidos & $1985-1987$ \\
\hline José Miguel Salazar & Venezuela & 1987-1989 \\
\hline Gerardo Marín & Estados Unidos & 1989-1991 \\
\hline Angela Biaggio & Brasil & 1991-1993 \\
\hline Martin Fishbein & Estados Unidos & 1993-1995 \\
\hline Euclídez Sánchez & Venezuela & 1995-1997 \\
\hline Bárbara Marín & Estados Unidos & 1997-1999 \\
\hline Susan Pick & México & 1999-2001 \\
\hline Bernardo Ferdman & Estados Unidos & $2001-2003$ \\
\hline Héctor Fernández Álvarez & Argentina & 2003-2005 \\
\hline Rolando Díaz-Loving & México & $2005-2007$ \\
\hline Andrés Consoli & Estados Unidos & 2007-2009 \\
\hline María Regina Maluf & Brasil & 2009-2011 \\
\hline José Toro-Alfonso & Puerto Rico & 2011-2013 \\
\hline
\end{tabular}

Fuente: Sociedad Interamericana de Psicología

\section{Congresos interamericanos}

La SIP ha organizado 33 congresos interamericanos de psicología, en diferentes países del continente americano. Se reconoce que estos congresos han favorecido positivamente al desarrollo de la psicología en aquellos países que fueron sedes. En la Tabla 3 se visualizan todos los congresos realizados, lugar y fecha de realización, responsable de la organización y cantidad de asistentes.

México es el país donde más congresos se han organizado, con 5 eventos en su historia. Argentina, Brasil, Estados Unidos y Perú le siguen con 3 organizaciones respectivamente. Con dos organizaciones se ubican: Chile, Colom- bia, República Dominicana, Puerto Rico y Venezuela. Hasta la fecha, solo se ha organizado un único congreso en Costa Rica, Cuba, Ecuador, Guatemala, Panamá y Uruguay.

Desde hace unos años, la SIP viene promoviendo los congresos regionales, para fortalecer la psicología como ciencia y profesión en aquellos países donde todavía es muy joven su desarrollo. El primero se llevó a cabo en Guatemala en 2004, el segundo en Cuba en 2006, el tercero en Paraguay en 2010 y el próximo está programado en Santa Cruz de la Sierra, Bolivia, en 2012.

En un comienzo, la asistencia a los congresos interamericanos apenas superaba los 500 participantes, mientras que en los últimos congresos se registra un promedio de 2000 participantes. Los estudiantes también fueron activos participantes en varios de los congresos realizados (Angelini, 1979). Además, la participación estudiantil ha sido valorada altamente protagónica no sólo en el seno de la SIP, sino también, en las infinitas actividades académicas, institucionales, políticas y científicas desarrolladas en la psicología de la región (Gallegos, 2009).

\section{Los grupos de trabajo}

Al interior de la SIP se han generado varios grupos de trabajo en diferentes áreas de la psicología (Tabla 4). Básicamente, estos grupos han tenido sus orígenes en los citados congresos interamericanos, debido a las coincidencias de intereses temáticos y el intercambio de información entre sus miembros.

Estos grupos están conformados por socios activos de la SIP y cumplen con el objetivo de desarrollar las líneas de trabajo planificadas, así como colaborar en la organización de los congresos interamericanos, entre otras tareas. Por ejemplo, el grupo de historia de la psicología ha organizado varios simposios sobre su materia, dos de los cuales han tenido como propósito homenajear el 50 y el 60 aniversario de la SIP, en Lima (2003) y en Medellín (2011), respectivamente.

Se encuentra en proceso de edición, una obra coordinada por Hugo Klappenbach y Ramón León, donde se presentarán varias autobiografías de psicólogos ligados a la historia de la SIP. A esto, cabe agregar un video histórico de la sociedad, donde se visualiza a varios de sus protagonistas más relevantes (Urra, 2003).

El grupo de psicología comunitaria ha publicado dos obras con las ponencias presentadas en los congresos interamericanos (Montero, 1997; Varas-Díaz \& Serrano-García, 2005). El grupo sobre formación en psicología ha promovido la organización y edición de varias obras colectivas (Toro \& Villegas, 2001; Villegas, Marassi, \& Toro, 2003a y b). También se destaca una obra compilada sobre la psicología en las Américas, donde se reúne una cantidad importante de información sobre la psicología interamericana (Alonso \& Eagly, 1999). 
Tabla 3

Congresos Interamericanos de Psicología

\begin{tabular}{|c|c|c|c|c|}
\hline Número & Lugar & Presidente del Comité & Asistentes & Año \\
\hline I & Santo Domingo, República Dominicana & Andrés Avelino García & 50 & 1953 \\
\hline II & Ciudad de México, México & Guillermo Dávila & 200 & 1954 \\
\hline III & Austin, Texas, Estados Unidos & Wayne Holtzman & 150 & 1955 \\
\hline IV & Rio Piedras, Puerto Rico & Marion García & 250 & 1956 \\
\hline $\mathrm{V}$ & Ciudad de México, México & Rogelio Díaz Guerrero & 350 & 1957 \\
\hline VI & Rio de Janeiro, Brasil & Lourenço Filho & 399 & 1959 \\
\hline VII & Ciudad de México, México & Guillermo Dávila & 650 & 1961 \\
\hline VIII & Mar del Plata, Argentina & Fernanda Monasterio & 600 & 1963 \\
\hline IX & Miami, Florida, Estados Unidos & Marshall Jones & 300 & 1964 \\
\hline $\mathrm{X}$ & Lima, Perú & Carlos Alberto Seguín & 466 & 1966 \\
\hline XI & Ciudad de México, México & Rogelio Díaz Guerrero & 900 & 1967 \\
\hline XII & Montevideo, Uruguay & Elida J. Tuana & 392 & 1969 \\
\hline XIII & Panamá, Panamá & Carlos Malgrat & 700 & 1971 \\
\hline XIV & São Paulo, Brasil & Arrigo Angelini & 3072 & 1973 \\
\hline $\mathrm{XV}$ & Bogotá, Colombia & José Antonio Sánchez & 2800 & 1974 \\
\hline XVI & Miami, Estados Unidos & Gordon Finley & 720 & 1976 \\
\hline XVII & Lima, Perú & Reynaldo Alarcón & 4000 & 1979 \\
\hline XVIII & Santo Domingo, República Dominicana & Rolando Tabar & 1600 & 1981 \\
\hline XIX & Quito, Ecuador & Nelson Serrano & 2000 & 1983 \\
\hline XX & Caracas, Venezuela & José Miguel Salazar & 2500 & 1985 \\
\hline XXI & La Habana, Cuba & Jorge Grau & 1500 & 1987 \\
\hline XXII & Buenos Aires, Argentina & Héctor Fernández Álvarez & 2540 & 1989 \\
\hline XXIII & San Jose, Costa Rica & Daniel Flores Mora & 2500 & 1991 \\
\hline XXIV & Santiago, Chile & Julio Villegas & 2500 & 1993 \\
\hline XXV & San Juan, Puerto Rico & Irma Serrano & 2000 & 1995 \\
\hline XXVI & São Paulo, Brasil & Maria Regina Maluf & 2200 & 1997 \\
\hline XXVII & Caracas, Venezuela & Maritza Montero & 1800 & 1999 \\
\hline XXVIII & Santiago, Chile & Antonio Mladinic & 1500 & 2001 \\
\hline XXIX & Lima, Perú & Cecilia Thorne & 1700 & 2003 \\
\hline XXX & Buenos Aires, Argentina & Mario Molina & 3757 & 2005 \\
\hline XXXI & Ciudad de México, México & Isabel Reyes Lagunes & 1200 & 2007 \\
\hline XXXII & Ciudad de Guatemala, Guatemala & María Pilar Grazioso & 1700 & 2009 \\
\hline XXXIII & Medellín, Colombia & Henry Castillo & 2254 & 2011 \\
\hline
\end{tabular}

Fuente: Sociedad Interamericana de Psicología

En el último congreso de la SIP en Medellín, Colombia, se estableció la constitución de un nuevo grupo de trabajo al interior de la SIP sobre editores de revistas en psicología, cuya dirección estaría a cargo de Wilson López López de la Universidad Javeriana, Colombia, quien ya en diversas oportunidades había organizado varios simposios $\mathrm{y}$ encuentros de editores en los congresos interamericanos.

\section{Premios interamericanos}

Como una forma de homenajear y destacar la trayectoria académica de importantes psicólogos en el continente americano, la SIP ha instituido los Premios Interamerica- nos de Psicología a partir de 1976 (Ardila, 1986; Brignardello, 1977). Tales premios son propuestos por miembros activos de la SIP y se otorgan cada dos años, durante la realización de los congresos interamericanos, a dos destacados psicólogos, uno de lengua hispana o portugués y otro de lengua inglés o francés (Tabla 5).

En dos ocasiones se entregaron premios póstumos: Carlos Albizu Miranda de Puerto Rico, en 1987 e Ignacio Martín Baró de El Salvador, en 1991. Como reconocimiento a la trayectoria de Rogelio Díaz Guerrero, desde el 2007, el premio interamericano para la versión hispana o portuguesa, lleva su nombre.

Desde 1991 se entregan los Premios Interamericanos Estudiantiles, a estudiantes de grado y de posgrado (Ferd- 
Tabla 4

Grupos de Trabajo (2009-2011)

\begin{tabular}{lll}
\hline Grupo de trabajo & Coordinador & País \\
\hline Psicología Ambiental & José Pinheiro & Brasil \\
Psicología Clínica & Diego Castrillón & Colombia \\
Psicología Comunitaria & Francheska Cintrón & Puerto Rico \\
Psicología y Educación & Aldo Bazán & México \\
Estudiantil & Marcelo Buenahora & Paraguay \\
& Migna Rivera & Puerto Rico \\
Ética y Deontología & Richard Tori & Perú \\
Historia de la Psicología & Ana Jacó & Brasil \\
& Ana Guzzi & Puerto Rico \\
Psicología Organizacional & Karisol Chevere & Puerto Rico \\
Formación y Entrenamiento en Psicología & Luis Ahumada & Chile \\
Psicología de la Salud & Ilia Rosario Nieves & Puerto Rico \\
Psicología del Tránsito y Seguridad Vial & Alfonso Urzúa & Chile \\
Psicología y Diversidades Sexuales & Mirta Fernández & Argentina \\
Violencia & David Ramírez & Costa Rica \\
Psicología y Pobreza & Silvia Pugliese & Argentina \\
\hline
\end{tabular}

Fuente: Sociedad Interamericana de Psicología

Tabla 5

Premios Interamericanos de Psicología (1976-2011)

\begin{tabular}{lll}
\hline Personas & Personas & \\
\hline Rogelio Díaz Guerrero (México) & Charles Osgood (Estados Unidos) & 1976 \\
Arrigo L. Angelini (Brasil) & Wayne H. Holtzman (Estados Unidos) & 1979 \\
Jacobo Varela (Uruguay) & Harry Triandis (Estados Unidos) & 1981 \\
Rubén Ardila (Colombia) & Herbert C. Kelman (Estados Unidos) & 1983 \\
Aroldo Rodrigues (Brasil) & David Belanger (Canadá) & 1985 \\
Emilio Ribes (México) & Martin Fishbein (Estados Unidos) \\
Eduardo Rivera Medina (Puerto Rico) & Robert J. Newbrough (Estados Unidos) \\
Premio Póstumo & Joseph Matarazzo (Estados Unidos) \\
José Miguel Salazar (Venezuela) & Sydney Bijou (Estados Unidos) \\
Maritza Montero (Venezuela) & Gerardo Marín (Estados Unidos) \\
Rolando Díaz-Loving (México) & Florence Denmark (Estados Unidos) \\
Héctor Fernández Álvarez (Argentina) & John Berry (Canadá) \\
Silvia Maurer Lane (Brasil) & John Adair (Canadá) \\
Euclides Sánchez (Venezuela) & Barbara Van Oss Marín (Estados Unidos) \\
Irma Serrano-García (Puerto Rico) & Robert Sternberg (Estados Unidos) \\
Isabel Reyes Lagunes (México) & Alice Eagly (Estados Unidos) \\
José Toro Alfonso (Puerto Rico) & Albert Bandura (Estados Unidos) \\
Susan Pick (México) & Judith Gibbons (Estados Unidos) & 1989 \\
\hline
\end{tabular}

Fuente: Sociedad Interamericana de Psicología

man, 2000; Ferdman \& VanOss, 1999). También se han otorgado varias menciones honoríficas. En la Tabla 6 se mencionan los nombres de los galardonados y sus respectivos países de procedencia.

Para acceder a estos premios, los estudiantes de grado y posgrado deben concursar con la presentación de algún trabajo, de acuerdo a las bases y plazos fijados por la SIP. Las evaluaciones y resultados se dan a conocer durante la realización de los congresos interamericanos. Los galardonados, además de exponer sus respectivos trabajos en el congreso de la SIP, reciben una ayuda económica para cubrir los gastos de asistencia al evento. 
Tabla 6

Premios Interamericanos Estudiantiles (1976-2011)

\begin{tabular}{|c|c|c|}
\hline Premio Pregrado & Premio Pregrado & Año \\
\hline Héctor Díaz Martínez (España) & Catalina Gandica de Gisbert (Venezuela) & 1991 \\
\hline Isabel Rodríguez Mora (Venezuela) & Gabina Villagrán Vásquez (México) & 1993 \\
\hline Carlos Silva y María Hernández (Venezuela) & Andrés J. Consoli (Argentina - Estados Unidos) & 1995 \\
\hline María Ximena Arias Garzón (Colombia) & Fayth M. Parks (Estado Unidos) & 1997 \\
\hline Jacques Moore (Canadá) & Emily Sáez Santiago (Puerto Rico) & 1999 \\
\hline Menciones honoríficas: Edna Acosta (Puerto Rico); & Menciones honoríficas: Ana María Anguas Plata (México); & \\
\hline Miguel Andrés Malagreta & María Annette Moreno Torres (Puerto Rico) & \\
\hline Yakeel Tatiana Quiroz Gaviria (Colombia), & Eduardo Cumba-Avilés, José J. Bauermeister, & 2001 \\
\hline María Antonieta Bobbes León (Cuba) & Maribel Matos, Carmen C. Salas & \\
\hline y Francisco Javier Lopera Restrepo (Colombia) & y Graciela Reina (Puerto Rico) & \\
\hline $\begin{array}{l}\text { Jaime A. Bayona, Iván R. Ruiz, Camilo Hurtado, } \\
\text { Andrés Hoyos y Carlos A. Gantiva (Colombia) }\end{array}$ & Marcelo Urra (Chile) & 2003 \\
\hline Alejandro Segura Beltrán (Colombia) & Tania Esmeralda Rocha Sánchez: (México) & 2005 \\
\hline Menciones honoríficas: Berenice Bedolla (México); & Menciones honoríficas: Guillermo Macbeth (Argentina); & \\
\hline Renán García Hernández (México) & María Teresa Estefanía Sánchez y Jessica O’Hara Bellina (Perú) & \\
\hline Vicente Cassepp-Borges y Maycoln Leô & María Elena Rivera Heredia (México) & 2007 \\
\hline ni Martins Teodoro (Brasil) & Menciones honoríficas: Diana Verónica Rivera Ottenberger (Chile) & \\
\hline Menciones honoríficas: Luciana Sofía Moretti (Argentina); & Karisol Chévere-Rivera, Mónica Vigo-Mockford & \\
\hline Mónica Gabriela Abraham, Romina Della Valentina, & y Martha Canales-Guzmán (Puerto Rico); & \\
\hline Sofía Paola Gauchat \& Julián Carlos Marino (Argentina) & Andrea Valeria Tognarelli Guzmán (Chile) & \\
\hline Rosario Costas Muñiz (Puerto Rico) & Filipe Degani-Carneiro (Brasil) & 2011 \\
\hline Mención honorífica: Fredy Alberto Mora Gámez (Colombia) & Mención honorífica: Ana Cristina Hermosillo Abundis (México) & \\
\hline
\end{tabular}

Fuente: Sociedad Interamericana de Psicología

\section{Publicaciones periódicas}

Además de las obras compiladas señaladas anteriormente, la SIP ha editado varias publicaciones periódicas. Inicialmente publicó un Boletín de Noticias en 1957, que luego fue titulado Psicólogo Interamericano, en 1976, y más tarde redefinido como Psicología Interamericana, a partir de 2007. También se recuerda la publicación del Spanish-Language Psychology (Anónimo, 1979) que fuera editado entre 1981 y 1983, con la finalidad de dar a conocer los trabajos que no pertenecían a la "lingua franca" de la ciencia (Cassepp, 2004; Marín, 1985).

La publicación más importante que ha favorecido la SIP es la Revista Interamericana de Psicología, editada desde 1967 (Ardila, 1986; Ferdman \& VanOss, 1999; Rodríguez, 1999). Esta revista no sólo es una de las publicaciones psicológicas internacionales más antigua que se encuentra en la región, sino además, una de las pocas que ha logrado mantener su continuidad en el tiempo. La Revista Latinoamericana de Psicología, fundada por Rubén Ardila en 1969, activo participante de la SIP, es otra de las publicaciones de antigua data que se pueden encontrar en América (Ardila, 1969, 1988, 1998; Gallegos, 2010b; Gutiérrez, Pérez-Acosta, \& Plata-Caviedes, 2009; López-López \& Calvache, 1998).
En la Tabla 7 se encuentran todos los nombres de los responsables de la edición de la Revista Interamericana de Psicología desde sus inicios hasta el presente.

Los idiomas oficiales de la revista son el inglés, el castellano y el portugués, y a partir de 1998 también el francés (Cassepp, 2004). Es interesante destacar que, gracias a un

Tabla 7

Editores de la Revista Interamericana de Psicología (19672011)

\begin{tabular}{lll}
\hline Nombre y Apellido & País & Período \\
\hline Carl F. Hereford & Estados Unidos & $1967-1970$ \\
Luis Natalicio & Estados Unidos & $1970-1975$ \\
Horacio Rimoldi & Argentina & $1975-1976$ \\
Gordon Finley & Estados Unidos & $1977-1982$ \\
Luis Laosa & Estados Unidos & $1983-1989$ \\
José Miguel Salazar & Venezuela & $1990-1998$ \\
Irma Serrano-García & Puerto Rico & $1998-2003$ \\
Silvia Helena Koller & Brasil & $2003-2010$ \\
Edil Torres Rivera & Estados Unidos & $2011-$ \\
\hline
\end{tabular}

Fuente: Sociedad Interamericana de Psicología 
proceso de digitalización y una política de open access, es posible contar con todos los artículos desde el primer número de la revista (Koller \& Trzesniak, 2003; Trzesniak \& Koller, 2005, 2010). Si bien en la página Web de la revista sólo es posible descargar los artículos desde el año 2000, no obstante, se pueden solicitar los artículos anteriores al editor responsable.

La revista ha publicado muchísimos artículos, reseñas, informes breves, secciones especiales, premios estudiantiles, etc. En sus páginas han publicado autores de todas partes del mundo, aunque predominantemente del continente americano. En un comienzo se publicaron más trabajos de autores norteamericanos y últimamente se están publicando más trabajos de autores latinoamericanos y caribeños (Cassepp, 2004; Maluf, 2004; Salazar, 1997; Serrano-García \& Resto-Olivo, 2003). Desde 1997 se selecciona el mejor trabajo publicado durante el período de dos años para otorgarle un premio (Ferdman, 2000; Ferdman \& VanOss, 1999).

\section{Conclusiones}

Durante el desarrollo del trabajo se ha documentado y contextualizado el tiempo de constitución de la SIP. También se ha podido reflejar las diversas gestiones realizadas por la SIP, tales como la organización de los congresos, la constitución de grupos de trabajo, la edición de obras compiladas y la edición de revistas periódicas, entre otras cosas.

Ahora es momento de justificar y dar razones de por qué es lícito postular el comienzo de la historia de la psicología interamericana con la fundación de la SIP. En gran medida, el desarrollo del trabajo ya ha contribuido a justificar esa historia. No obstante, se pueden agregar algunas razones más.

La historia de la psicología interamericana, con su complejidad idiomática, cultural, científica, política, académica, institucional y geográfica, comienza con la creación de la SIP, en diciembre de 1951. Hasta el momento, no existe otro dato $o$ acontecimiento anterior a esa fecha que pueda señalarse como inaugural. Tampoco puede indicarse otra circunstancia histórica que refleje la conexión de la psicología interamericana, que sí posibilitó el comienzo de las actividades de la SIP. Antes de la SIP, la psicología del sur y la psicología del norte transitaban por caminos adyacentes.

Entonces, ¿qué es la historia de la psicología interamericana? No sólo es la historia de la creación de la SIP, sus mentores, sus actividades, sus logros y sus realizaciones, como ya muchos autores han puesto de manifiesto. La historia de la psicología interamericana es, también, la historia de las conexiones.

Es la historia de como se conectaron dos exiliados alemanes, uno que vivía en Argentina (Krapf) y otro que moraba en Estados Unidos (Wolff), con un canadiense (Line), un guatemalteco (Barrios Peña), un mexicano (Robles), un chileno (Nassar), un colombiano (Vergara) y un brasileño (Roxo) para formar una institución interamericana de psicología. Gracias a esa primera conexión, que lógicamente tiene sus antecedentes, se posibilitaron nuevas conexiones. Sin embargo, como en un proceso neuronal, además de nuevas conexiones, también hubo podas.

En el primer congreso de la SIP, en la República Dominica, en 1953, Krapf no participaría y Robles sería el protagonista de las gestiones iniciales. De hecho, fue Robles, en su posición de secretario general, quien se contactaría con Andrés Avelino, pensador dominicano al que había conocido unos años antes en el Primer Congreso Nacional de Filosofía, celebrado en Mendoza, Argentina, en 1949. Avelino fue el responsable de materializar el primer congreso de la SIP. Ese primer congreso tiene un valor simbólico muy importante, dado que su realización afianzó los objetivos de vincular a los psicólogos del continente americano (Rodríguez, 2000).

Un dominicano, Tirso Mejía Ricart, siendo estudiante de medicina, que por ese entonces estuvo presente en el primer congreso de la SIP, años más tarde, recobrando el interés por la psicología, llegó a ser uno de los creadores de la carrera de psicología en la República Dominicana (Mejía Ricart, 1975).

Carlos Nassar, quien fuera elegido el primer vicepresidente para Sudamérica, fue uno de los que inició formalmente la capacitación de psicólogos en Chile en 1946. Aunque no estuvo presente en el primer congreso de la SIP, el trabajo que envío y que fuera leído por Víctor Funes Donaire, se refería al primer programa de formación en psicología en Chile (Nassar, 1955). Funes Donaire, de origen hondureño, no sólo había sido uno de los primeros estudiantes de aquel programa, sino además, uno de los primeros graduados y uno de los primeros en reportar el título de psicólogo en Honduras (Donaire, 2002).

Por su parte, el primer congreso de la SIP que se celebraría en Estados Unidos, en 1955, luego de los realizados en Santo Domingo en 1955 y México en 1956, ocurre gracias a otras conexiones. Fue Wolff, en su carácter de vicepresidente, el encargado de contactar a Wayne Holtzman, para solicitarle su colaboración en la organización del evento (Colotla \& Urra, 2006; Holtzman, 2002). En ese tercer evento de la SIP, se fortificaron y crecieron los lazos entre el mexicano Rogelio Díaz Guerrero y el norteamericano Wayne Holtzman, quienes más tarde llegarían a ser presidentes de la SIP y recibirían el Premio Interamericano de Psicología.

Como se ha documentado, fue a partir de ese congreso que se iniciaron diversos intercambios académicos, profesionales y estudiantiles entre el Colegio de Psicología de la Universidad Nacional de México y el Departamento de Psicología de la Universidad de Texas. Más específicamente, a partir de esas vinculaciones se desarrolló todo un programa de investigación transcultural que duró varios años (Carrascoza, 2003; Díaz-Guerrero, 1971, 1994b, 1995; Holtzman, 2002). 
Así se establecieron las primeras conexiones de la psicología interamericana. Tengamos presente que esas conexiones son muy diferentes a las que se establecen en el presente. En la actualidad, talas conexiones siguen siendo múltiples y diversas, aunque se tramiten por canales comunicacionales diferentes. Se podría seguir documentando más conexiones, pero no nos alcanzarían las páginas. Baste con señalar que las conexiones que se propiciaron hacia mitad de siglo XX entre la psicología del sur, centro, caribe y norte todavía se mantienen. Esas conexiones son las razones históricas de la psicología interamericana.

\section{Referencias}

Actas (1955). Actas del Primer Congreso Interamericano de Psicología. Ciudad Trujillo, República Dominicana: Editora del Caribe.

Adair, J. (1999). Psychology in Canada. En M. Alonso \& A. Eagly (Eds.), Psicología en las Américas (pp. 87-97). Caracas, Venezuela: Sociedad Interamericana de Psicología.

Alarcón, R. (2000). Historia de la psicología en el Perú. De la Colonia a la República. Lima, Perú: Universidad Ricardo Palma.

Alarcón, R. (2002). Estudios sobre psicología latinoamericana. Lima, Perú: Universidad Ricardo Palma/Editorial Universitaria.

Alarcón, R. (2004). Medio siglo de psicología latinoamericana: Una visión de conjunto. Revista Interamericana de Psicología, 38(2), 307-316.

Alonso, M., \& Eagly, A. (Eds.) (1999). Psicología en las Américas. Caracas, Venezuela: Sociedad Interamericana de Psicología.

Alonso, M., \& Nicenboim, E. (1999). Comentario y cronología de la psicología en las Américas. En M. Alonso \& A. Eagly (Eds.), Psicología en las Américas (pp. 383-388). Caracas, Venezuela: Sociedad Interamericana de Psicología.

Álvarez-Salgado, I. (2000). Una historia de la psicología en el Caribe Isleño. Revista Interamericana de Psicología, 34(2), 235-256.

Álvarez, A., \& Bonilla, J. (1995). Entrevistas con pioneros de la SIP. Revista Interamericana de Psicología, 29(1), 105-138.

Angelini, A. (1979). O papel da Sociedade Interamericana de Psicologia no desenvolvimento da psicología na América Latina. Revista Interamericana de Psicología, 13(1-2), 5-25.

Anónimo. (1892). The International Congress of Experimental Psychology. The British Medical Journal, 6, 313-314.

Anónimo. (1976). El XXI Congreso Internacional de Psicología (Paris). Revista Latinoamericana de Psicología, 8(3), 495.

Anónimo (1979). A nuestros lectores. Revista Interamericana de Psicología, 13(1-2), 3.

Antunes, M. (1995). A psicologia no Brasil. Leitura histórica sobre sua constituição. São Paulo, Brasil: Unimarco/Educ.

Ardila, R. (1969). Presentación. Revista Latinoamericana de Psicología, l(1), v-vi.
Ardila, R. (1971). Los pioneros de la psicología. Buenos Aires, Argentina: Paidós.

Ardila, R. (1972). La psicología contemporánea. Panorama internacional. Buenos Aires, Argentina: Paidós.

Ardila, R. (1973). La psicología en Colombia: Desarrollo histórico. México: Trillas.

Ardila, R. (1986). La psicología en América Latina: Pasado, presente y futuro. México: Siglo XXI.

Ardila, R. (1988). Los 20 primeros años de la Revista Latinoamericana de Psicología. Revista Latinoamericana de Psicología, 20(3), 401-406.

Ardila, R. (Ed.) (1993). Psicología en Colombia. Contexto social e histórico. Bogotá, Colombia: TM.

Ardila, R. (1998). La Revista Latinoamericana de Psicología: Los primeros 30 años. Revista Latinoamericana de Psicología, 30(3), 393-400.

Ardila, R. (2004). A psicología latinoamericana: El primer medio siglo. Revista Interamericana de Psicología, 38(2), $317-$ 323.

Bell, D. (1973). El advenimiento de la sociedad post-industrial. Madrid, España: Alianza.

Benito, E. (2009). La formación en psicología: Revisión y perspectivas. Psiencia, 1(2), 3-10.

Benjamin, L. (2001). American psychology's struggles with its curriculum: Should a thousand flowers bloom? American Psychologist, 56(9), 735-742. http://dx.doi.org/10.1037//0003066X.56.9.735

Ben-David, J. (1974). El papel de los científicos en la sociedad. México: Trillas.

Bercherie, P. (1988). Génesis de los conceptos freudianos. Buenos Aires, Argentina: Paidós.

Bernal, J. (1979). La ciencia en nuestro tiempo. México: UNAM/ Nueva Imagen.

Boring, E. (1978). Historia de la psicología experimental. México: Trillas.

Bravo, L. (2004). Cincuenta años de psicología en la Universidad Católica. Psykhe, 13(1), 197-204. http://dx.doi.org/10.4067/ S0718-22282004000100016

Brett, G. (1972). Historia de la psicología. Buenos Aires, Argentina: Paidós.

Brignardello, L. (1977). Acerca del XVI Congreso Interamericano de Psicología. Revista Latinoamericana de Psicología, 9(2), 332-334.

Camfield, T. (1973). The professionalization of American Psychology, 1870-1917. Journal of the History of Behavioral Sciences, 9, 66-75. http://dx.doi.org/10.1002/1520-6696(197301) 9:1<66::AID-JHBS2300090108>3.0.CO;2-X

Carpintero, H. (1993). Relaciones entre España e Iberoamérica en el campo de la psicología. Interacción Social, 3, 25-46.

Carpintero, H. (1994). Historia de la psicología en España. Madrid, España: Eudema.

Carpintero, H. (1997). Los psicólogos españoles emigrados y su proyección iberoamericana. En V. Aparicio (Ed.), Orígenes y fundamentos de la psiquiatría en España (pp. 179-192). Madrid, España: ELA. 
Carpintero, H. (2004). Medio siglo de la psicología en España: 1950-2000. Revista Interamericana de Psicología, 38(2), 343350.

Carpintero, H. (2005). La psicología iberoamericana. Una perspectiva según el método histórico de las generaciones. Revista de Historia de la Psicología, 26(1), 41-56.

Carrascoza, C. (2003). Rogelio Díaz Guerrero: Pionero de la psicología experimental en México. Psicología y Ciencia Social, 5(2), 3-22.

Cassepp, V. (2004). Los 38 años de historia de la Revista Interamericana de Psicología. Revista Interamericana de Psicología, $38(2), 369-372$.

Conway, J. (2010). A chronicle of the activities of the Canadian Psychological Association 1938-2000. Ottawa, Canadá: Canadian Psychological Association.

Cook, S. (1965). The scientist-proffesional: Can psychology carry it off? Canadian Psychologist, 6, 93-109. http://dx.doi.org/ 10.1037/h0083062

Colotla, V., \& Urra, M. (2006). Semblanza biográfica de los fundadores de la Sociedad Interamericana de Psicología. Revista Interamericana de Psicología, 40(3), 377-384.

Dagfal, A. (2009). Entre París y Buenos Aires. La invención del psicólogo (1942-1966). Buenos Aires, Argentina: Paidós.

Díaz-Guerrero, R. (1971). La enseñanza de la investigación en psicología en Iberoamérica: Un paradigma. Revista Latinoamericana de Psicología, 3(1), 5-36.

Díaz-Guerrero, R. (1994a). Origins and development of psychology in Latin America. International Journal of Psychology, 29(6), 717-727. http://dx.doi.org/10.1080/00207599408246561

Díaz-Guerrero, R. (1994b). Psicología del desarrollo humano (autobiografía). En P. Valderrama, V. Colotla, X. Gallegos, \& S. Jurado (Comps.), Evolución de la psicología en México (pp. 107-135). México: El Manual Moderno.

Díaz-Guerrero, R. (1995). Una aproximación científica a la etnopsicología. Revista Latinoamericana de Psicología, 27(3), 359389.

Díaz-Guerrero, R. (2004). 50 años de psicología interamericana: Una visión desde México. Revista Interamericana de Psicología, 38(2), 333-342.

Donaire, V. (2002). Historia de la psicología en Honduras. Tegucigalpa, Honduras: Universidad Nacional Autónoma de Honduras.

Elzinga, A., \& Jamison, A. (1996). El cambio de las agendas políticas en ciencia y tecnología. Zona Abierta, 75-76, 91-132.

Fancher, R. (1979). Pioneers of psychology. New York, NY: Norton \& Company.

Farr, R. (1998). As raízes da psicologia moderna. Petrópolis: Vozes. Ferdman, B. (2000). The Interamerican Society of Psychology. En A. E. Kazdin (Ed.), Encyclopedia of psychology (Vol. 4. pp. 324-326). Washington, WA: American Psychological Association.

Ferdman, B., \& VanOss, B. (1999). Interamerican Society of Psychology: History and current status. En A. Modesto \& A. Eagly (Eds.), Psicología en las Américas (pp. 353-359). Caracas, Venezuela: Sociedad Interamericana de Psicología.
Filho, L. (1970). A psicologia no Brasil nos últimos 25 anos. Rio de Janeiro, Brasil: Fundação Getúlio Vargas.

Fraisse, P., \& Piaget, J. (1976). Historia y método de la psicología experimental. Buenos Aires, Argentina: Paidós.

Gallegos, M. (2005). Cincuenta años de historia de la psicología como institución universitaria en Argentina. Revista Latinoamericana de Psicología, 37(3), 641-652.

Gallegos, M. (2008). La formación académica y profesional del psicólogo en América Latina: Aportes para un debate desde los indicadores curriculares en Argentina. Actas del VI Congreso Iberoamericano de Psicología, Lima, Perú.

Gallegos, M. (2009). Movimiento y participación estudiantil en la psicología latinoamericana: Consideraciones históricas y futuras perspectivas. Avances en Psicología Latinoamericana, 27(1), 33-60.

Gallegos, M. (2010a). La Primera Conferencia Latinoamericana sobre entrenamiento en psicología: El modelo latinoamericano y su significación histórica. Psicologia: Ciência e Profissão, 30(4), 792-809.

Gallegos, M. (2010b). La Revista Latinoamericana de Psicología en sus 40 años de historia: 1969-2009. Universitas Psychologica, 9(3), 911-924.

Gallegos, M. (2011). Book review: Historia de la psicología en Chile: 1889-1981. Cuadernos de Neuropsicología, 5(1), 89-94.

Gallegos, M. (en prensa). El Primer Congreso Interamericano de Psicología (1953): Su acontecer histórico. Revista Interamericana de Psicología, 45(3).

Gallegos, M., Reynaldo, L., \& Catini, T. (2010). Una visión panorámica de la profesionalización de la psicología en América Latina. Memorias del II Congreso Internacional de Investigación y Práctica Profesional en Psicología, XVII Jornadas de Investigación y Sexto Encuentro de Investigadores en Psicología del MERCOSUR, T. III, pp. 84-87. Facultad de Psicología. Universidad de Buenos Aires.

Galperín, P. (1976). Introducción a la psicología. Madrid, España: Pablo del Río.

García, J. (2004). La evolución de la psicología en el Paraguay: Una evaluación desde el modelo de Hiroshi Azuma. Revista Intercontinental de Psicología y Educación, 6(2), 25-36.

García, J. (2005). El joven Eusebio Ayala y la psicología paraguaya. Teoría e Investigación en Psicología, 14, 46-90.

García, J. (2006). Relaciones históricas entre la psicología y la educación en el Paraguay. Psicologia da Educaçâo, 22, 95-137.

García, J. (2007). La psicología en Paraguay y el problema de la determinación de los pioneros. Revista Intercontinental de Psicología y Educación, 9(2), 113-146.

García, J. (2008). Ramón Indalecio Cardozo como pionero de la psicología en el Paraguay. Revista Interamericana de Psicología, 42(1), 171-180.

García, J. (2010). La cátedra de psicología experimental en la Universidad Católica de Asunción: 1985-1987. Revista Interamericana de Psicología, 44(1), 157-167.

García-Vega, L. (1993). Historia de la psicología. La psicología rusa: Reflexología y psicología soviética. Vol. III. Madrid, España: Siglo XXI. 
García-Vega, L., \& Moya-Santoyo, J. (1993). Historia de la psicología. Teorías y sistemas psicológicos contemporáneos. Vol. II. Madrid, España: Siglo XXI.

García-Vega, L., Moya-Santoyo, J., \& Rodríguez-Domínguez, S. (1992). Historia de la psicología. Introducción. Vol. I. Introducción. Madrid, España: Siglo XXI.

Garrett, H. (1962). Las grandes realizaciones en la psicología experimental. México: F.C.E.

Gentile, A. (2003). Ensayos históricos sobre psicoanálisis y psicología. Rosario, Argentina: Ross.

Geuter, U., \& León, R. (1997). The emigration of European psychologists to Latin America. Cuadernos Argentinos de Historia de la Psicología, 3(1/2), 67-98.

Gomes, A. (1992). História da psicologia no Rio de Janeiro. Rio de Janeiro, Brasil: Imago.

Guillaume, P. (1959). Manual de psicología. Buenos Aires, Argentina: Paidós.

Gutiérrez, G., Pérez-Acosta, A., \& Plata-Caviedes, T. (2009). Desarrollo histórico de una publicación científica: Cuarenta años de la Revista Latinoamericana de Psicología. Revista Latinoamericana de Psicología, 41(3), 413-428.

Heidbreder, E. (1979). Psicologías del siglo XX. Buenos Aires, Argentina: Paidós.

Hobsbawm, E. (2007). Historia del siglo XX. Buenos Aires, Argentina: Crítica.

Holtzman, W. (1976). The XXVth Anniversary of the International Union of Psychological Science. International Journal of Psychology, 11(2), 121-136. http://dx.doi.org/10.1080/00207597 608247353

Holtzman, W. (1979). Algunas reflexiones personales sobre veinticinco años de psicología interamericana. En G. Finley \& G. Marín (Eds.), Avances en psicología contemporánea (pp. 3-5). México: Trillas.

Holtzman, W. (2002). Over half a century of playing with inkblots and other wondrous pursuits. Journal of Persoanlity Assessment, 79(1), 1-18. http://dx.doi.org/10.1207/S15327752JPA 7901 01

Jacó-Vilela, A. (2000). Psicólogos estrangeiros no Brasil. Cadernos do IPUB, 6(18), 37-52.

Klappenbach, H. (1998). Formas organizativas de la psicología en la Argentina. Idea, 27, 21-41.

Klappenbach, H. (2002). La psicología en la Argentina en el período de entreguerras. Saber y Tiempo, 13, 133-162.

Klappenbach, H. (2003). La globalización y la enseñanza de la psicología en Argentina. Psicologia em Estudo, 8(2), 3-18. http://dx.doi.org/10.1590/S1413-73722003000200002

Klappenbach, H. (2004). Eduardo Krapf (1901-1963): Primer presidente de la Sociedad Interamericana de Psicología. Revista Interamericana de Psicología, 38(2), 361-368.

Klappenbach, H. (2006). Periodización de la psicología en Argentina. Revista de Historia de la Psicología, 27(1), 109164.

Klappenbach, H., \& Pavesi, P. (1994). Una historia de la psicología en Latinoamérica. Revista Latinoamericana de Psicología, 26(3), 445-482.
Koller, S., \& Trzesniak, P. (2003). La RIP 2003-2006: Trasparencia de procedimientos y visibilidad de contenidos. Revista Interamericana de Psicología, 37(2), 205-210.

Langfeld, H. (1955). Relaciones internacionales en psicología. Actas del Primer Congreso Interamericano de Psicología (pp. 369-372). Ciudad Trujillo, República Dominicana: Editora del Caribe.

León, R. (1993). Contribuciones a la historia de la psicología en el Perú. Lima, Perú: CONCYTEC.

León, R. (1997). Rumbo al nuevo mundo: Cuatro psicólogos de Europa Oriental en la historia de la psicología en América del Sur. Revista Latinoamericana de Psicología, 29(1), 9-34.

León, R., \& Gueter, U. (1993). Al otro lado del mundo: Nota sobre los emigrantes europeos (1) en la psicología latinoamericana. Revista Intercontinental de Psicología y Educación, 6(1/2), 63-98.

Ligüeño, S., \& Parra, D. (2007). La psicología en la Universidad de Chile: Una propuesta de estudio para comprender la historia de la psicología en Chile. Cuadernos de Neuropsicología, 1(3), 223-235.

López-López, W., \& Calvache, O. (1998). La psicología de habla hispana: 30 años de la Revista Latinoamericana de Psicología. Revista Latinoamericana de Psicología, 30(3), 401-427.

Lunt, I. (2005). Reaching the parts that need it? The Psychologist, $18(2), 78-79$.

Lunt, I., \& Poortinga, Y. (1996). Internationalising psychology: The case of Europe. American Psychologist, 51, 504-508. http://dx.doi.org/10.1037//0003-066X.51.5.504

Maluf, R. (2004). A participação de psicólogos brasileiros na Sociedade Interamericana de Psicologia: Contribuições e perspectivas. Revista Interamericana de Psicología, 38(2), 323-332.

Marín, G. (1985). Difusión internacional de la psicología iberoamericana: Dimensiones del problema. Revista Mexicana de Psicología, 2(1), 12-19.

Massimi, M. (1990). História da psicologia brasileira. Da época colonial até 1934. São Paulo, Brasil: EPU.

Mejía Ricart, T. (1975). La psicoterapia en la República Dominicana. Revista Interamericana de Psicología, 9(1/2), 125-129.

McGovern, T. (1992). Evolution of undergraduate currícula in psychology, 1892-1992. En A. Puente, J. Matthews, \& C. Brewer (Eds.), Teaching psychology in America: A history (pp. 13-38). Washington, WA: American Psychological Association.

Montero, M. (Ed.) (1997). Psicología y comunidad. Memorias de la psicología comunitaria. XXV Congreso Interamericano de Psicología. San Juan, Venezuela: Universidad Central de Venezuela/ Sociedad Interamericana de Psicología.

Montoro, L., Carpintero, H., \& Tortosa, F. (1983). Los orígenes de los congresos internacionales de psicología. Revista de Historia de la Psicología, 4(1), 43-57.

Mueller, F. (1976). Historia de la psicología. Madrid, España: F.C.E.

Nassar, C. (1955). Experiencias recogidas en torno a la preparación profesional del psicólogo en Chile. Actas del Primer Congreso Interamericano de Psicología (pp. 571-586). Ciudad Trujillo, República Dominicana: Editora del Caribe. 
Nuttin, J. (1976). The role of the International Union of Psychological Science. International Journal of Psychology, 11(4), 299-304. http://dx.doi.org/10.1080/00207597608247365

Piéron, H. (1954). Histoire succincte des congrès internationaux de psychologie. L'Année Psychologique, 54(2), 397-405. http://dx.doi.org/10.3406/psy.1954.8737

Price, D. (1973). Hacia una ciencia de la ciencia. Barcelona, España: Ariel.

Reuchlin, M. (1973). Historia de la psicología. Buenos Aires, Argentina: Paidós.

Robles, O. (1955). Informe que la Secretaría General de la SIP rinde ante el Primer Congreso Interamericano de Psicología en relación con sus labores y gestiones efectuadas durante los años de 1952-53. Actas del Primer Congreso Interamericano de Psicología (pp. 744-752). Ciudad Trujillo, República Dominicana: Editora del Caribe.

Roca de Torres, I. (2003). Problemas centrales para la formación académica y el entrenamiento profesional en el Caribe. En J. Villegas, P. Marassi, \& J. Toro (Eds.), Problemas centrales para la formación académica y el entrenamiento profesional del psicólogo en las Américas (Vol. II. pp. 87-106). Santiago de Chile, Chile: Sociedad Interamericana de Psicología.

Rodríguez, P. (1999). Diez años de la Revista Interamericana de Psicología. En A. Modesto \& Eagly, A. (Eds.), Psicología en las Américas (pp. 361-382). Caracas, Venezuela: Sociedad Interamericana de Psicología.

Rodríguez, E. (2000). Antecedentes de la psicología en República Dominicana. Revista Interamericana de Psicología, 34(2), 37-56.

Rosenzweig, M., \& Holtzman, W. (1993). About the International Union of Psychological Science (IUPSYS). International Journal of Psychology, 28(3), 377-405. http://dx.doi.org/10.1080/ 00207599308246928

Rosenzweig, M., Holtzman, W., Sabourin, M., \& Bélanger, D. (2000). History of the International Union of Psychological Science. Philadelphia, PA: Psychology Press.

Rossi, L. (1994). Psicología en argentina. Capitulos olvidados de una historia reciente. Buenos Aires, Argentina: Tekné.

Rossi, L. (1997). La psicología antes de la profesión. Buenos Aires, Argentina: EUDEBA.

Rossi, L. (Comp.) (2005). Psicología en Argentina. Vestigios de profesionalización temprana. Buenos Aires, Argentina: JVE Ediciones.

Rusell, R. (1966). The International Union of Psychological Science. International Journal of Psychology, 1(1), 65-72. http://dx.doi.org/10.1080/00207596608247045

Salas, G. (2010). Contexto sociocultural de la psicología científica en Chile en el período 1875-1910. Reflexión Virtual, 2, 13-18.

Salas, G., \& Lizama, E. (2009). Historia de la psicología en Chile: 1889-1981. La Serena, Chile: Universidad de La Serena.

Salazar, J. (1997). La investigación transcultural en 30 años de la Revista Interamericana de Psicología. Revista Interamericana de Psicología, 31(2), 169-184.

Salomon, J. (1996). La ciencia y la tecnología modernas. En J. Salomon, F. Sagasti, \& C. Sachs (Comps.), La búsqueda incierta: Ciencia, tecnología y desarrollo. México: Fondo de Cultura Económica.

Sánchez-González, J. (2003). La formación del psicólogo en una perspectiva internacional. Una breve selección documental comprada. Bogotá, Colombia: Universidad El Bosque.

Sánchez-Sosa, J. (comp.) (1997). 100 años de la psicología en México 1896-1996. México: UNAM.

Sánchez-Sosa, J., \& Valderrama-Iturbe, P. (2001). Psychology in Latin America: Historical reflections and perspectives. International Journal of Psychology, 36(6), 384-394. http://dx.doi. org/10.1080/00207590143000216

Serrano-García, I., \& Resto-Olivo, J. (2003). La Revista Interamericana de Psicología: Debut y despedida. Revista Interamericana de Psicología, 37(1), 13-29.

Stubbe, H. (1988). Sobre la recepción de la psicología europea en America Latina. Archivo Latinoamericano de Historia de Psicología y Ciencias Afines, 1(1), 51-62.

Talak, A. (2000). Los primeros desarrollos académicos de la psicología en la Argentina (1896-1919). En J. Ríos, J. Stagnaro, \& P. Weissmann (Eds.), Psiquiatría, psicología y psicoanálisis. Historia y memoria (pp. 215-230). Buenos Aires, Argentina: Polemos.

Telford, C., \& Sawrey, J. (1977). Tratado de psicología. Buenos Aires, Argentina: Paidós.

Thompson, W., \& DeBold, R. (1980). Introducción sistemática a la psicología. Barcelona, España: Paidós.

Toro, J., \& Villegas, J. (Eds.) (2001). Problemas centrales para la formación académica y el entrenamiento profesional del psicólogo en las Américas. Vol. I. Buenos Aires, Argentina: Sociedad Interamericana de Psicología.

Torre, C. (1991). Temas actuales de historia de la psicología. La Habana, Cuba: ENPES.

Torre, C. (2010). Psicología latinoamericana. Entre la dependencia y la identidad. Buenos Aires, Argentina: Koyatún.

Trzesniak, P., \& Koller, S. (2005). Open access research: The ants and bees tale. Revista Interamericana de Psicología, 39(3), 321-324.

Trzesniak, P., \& Koller, S. (2010). Time to change: A journal about itself. Revista Interamericana de Psicología, 44(3), 411-414.

Urra, M. (2003). Psicología interamericana. Video histórico de la Sociedad Interamericana de Psicología. San Juan, Puerto Rico: Sociedad Interamericana de Psicología.

Urra, M. (2004). Psicología interamericana: Una historia. Psicólogo Interamericano, 84, 1-2.

Valderrama, P., Colotla, V., Gallegos, X., \& Jurado, S. (1994). Evolución de la psicología en México. México: El Manual Moderno.

Varas-Díaz, N., \& Serrano-García, I. (Ed.) (2005). Psicología comunitaria: Reflexiones, implicaciones y nuevos rumbos. San Juan, Puerto Rico: Publicaciones Puertorriqueñas

Vezzetti, H. (1988). Estudio preliminar. En H. Vezzetti (Ed.), El nacimiento de la psicología en la Argentina (pp. 11-34). Buenos Aires, Argentina: Puntosur.

Vilanova, A., \& Di Doménico, C. (1999). La psicología en el Cono Sur. Datos para una historia. Mar del Plata, Argentina: Universidad Nacional de Mar del Plata. 
Villegas, J. (2004). Sociedad Interamericana de Psicología (SIP): Cincuenta años de logros y desafíos. Revista Interamericana de Psicología, 38(2), 303-306.

Villegas, J, Marassi, P., \& Toro, J. (Eds.) (2003a). Problemas centrales para la formación académica y el entrenamiento profesional del psicólogo en las Américas. Vol. II. Santiago de Chile, Chile: Sociedad Interamericana de Psicología.

Villegas, J, Marassi, P., \& Toro, J. (Eds.) (2003b). Problemas centrales para la formación académica y el entrenamiento profesional del psicólogo en las Américas. Vol. III. Santiago de Chile, Chile: Sociedad Interamericana de Psicología.
Wright, M. (1974). CPA: The first ten years. Canadian Psychologist, 15(2), 112-131. http://dx.doi.org/10.1037/h0081744 Wolff, W. (1970). Introducción a la psicología. México: F.C.E. Zazzo, R. (1964). La psicología norteamericana. Buenos Aires, Argentina: Paidós.

Zunini, G. (1965). Psicología. Barcelona, España: Plaza \& Janes.

Received February 21, 2012

Revision received March 21, 2012

Accepted March 26, 2012 